\title{
Productivity evaluation of horizontal well in heterogeneous reservoir with composite water aquifer
}

\author{
Hui Yuan ${ }^{1}$. Wenhong $\mathrm{Li}^{1} \cdot$ Yingzhong Yuan ${ }^{2} \oplus \cdot$ Jiao Luo ${ }^{1} \cdot$ Wende Yan $^{2}$
}

Received: 11 September 2020 / Accepted: 27 January 2021 / Published online: 17 February 2021

(c) The Author(s) 2021

\begin{abstract}
Horizontal well is an important way to develop thin reservoir with edge-bottom water aquifer. For the horizontal well near oil-water contact, the reservoir have the features of edge water and bottom water at the same time. The productivity formula of horizontal well in pure edge water or pure bottom water reservoir is not fully applicable to this type of reservoir. For the heterogeneous reservoir with composite water aquifer, the horizontal well is divided into multiple well sections by using the concept of multi-segment well. Based on the seepage mechanics theory and potential superposition principle, considering the mutual interference between multi well sections, the productivity formula of horizontal well in heterogeneous reservoir with composite water aquifer is established. The new productivity formula considers the effect of reservoir heterogeneity, the quasi-linear flow of lateral edge water and the ellipsoidal flow of vertical bottom water. It can effectively determine the influence range and drainage distance of edge water in a heterogeneous reservoir with composite water aquifer. According to the test data of horizontal wells in Weizhou 11-1 oilfield, the drainage distance $b$ of edge water is fitted and used to predict the productivity of new wells, and the result is very good. The research result lays a foundation for productivity prediction of horizontal well in heterogeneous reservoir with composite water aquifer.
\end{abstract}

Keywords Heterogeneous reservoir with composite water aquifer $\cdot$ Heterogeneity $\cdot$ Drainage distance of edge water · Horizontal well $\cdot$ Productivity evaluation

\section{Introduction}

Horizontal well is an important way to develop bottom water reservoir, which can significantly increase oil drainage area, improve well productivity, delay or inhibit coning of bottom water (Al Zarafi 1993; Wibowo et al. 2004; Huo et al. 2010; Luo et al. 2015; Akangbou et al. 2017). In the early research stage of horizontal well development technology, the works mainly focus on the calculation of horizontal well productivity and critical production rate (Chaperon 1986; Joshi 1988; Giger 1989; Fan 1993; Lü 1993; Fan and Lin 1994). With the further research, bottom water coning phenomenon and calculation of breakthrough time are paid more and more attention (Al-Enezi et al. 2010; Permadi and Jayadi 2010;

Yingzhong Yuan

yuanyingzh0001@126.com

CNOOC Zhanjiang Branch, Zhanjiang 524057, China

2 Chongqing Key Laboratory of Complex Oil \& Gas Fields Exploration and Development, Chongqing University of Science and Technology, Chongqing 401331, China
Nobakht et al. 2013; Adewole 2014; Al-Fatlawi et al. 2019; Sharma et al. 2019; Yue et al. 2019). With the improvement of experimental means, a lot of visualization research on bottom water coning are done, intuitive and mechanism understandings about bottom water movement law are obtained (Wang et al. 2018; You et al. 2019).

Horizontal well productivity is influenced by many factors including reservoir physical property and heterogeneity, horizontal length, pay thickness, offset from water oil contact and skin factor, etc. (Hagoort 2009; Kumar et al. 2017; Su et al. 2018). However, the relationship between horizontal well and water aquifer, flow direction of fluid in reservoir have not been considered comprehensively. In a real reservoir, if a horizontal well is near the reservoir boundary, it is difficult to strictly define it as an edge water or bottom water reservoir (Fig. 1). When the vertical connectivity and permeability of reservoir with composite water aquifer are good, the fluid mainly moves from bottom water to horizontal well [Fig. 2(a)]; when the vertical connectivity is poor or there are interlayers, the flssuid mainly moves from edge water to horizontal well [Fig. 2(b)]. In the 
Fig.1 Diagram of reservoir with composite water aquifer

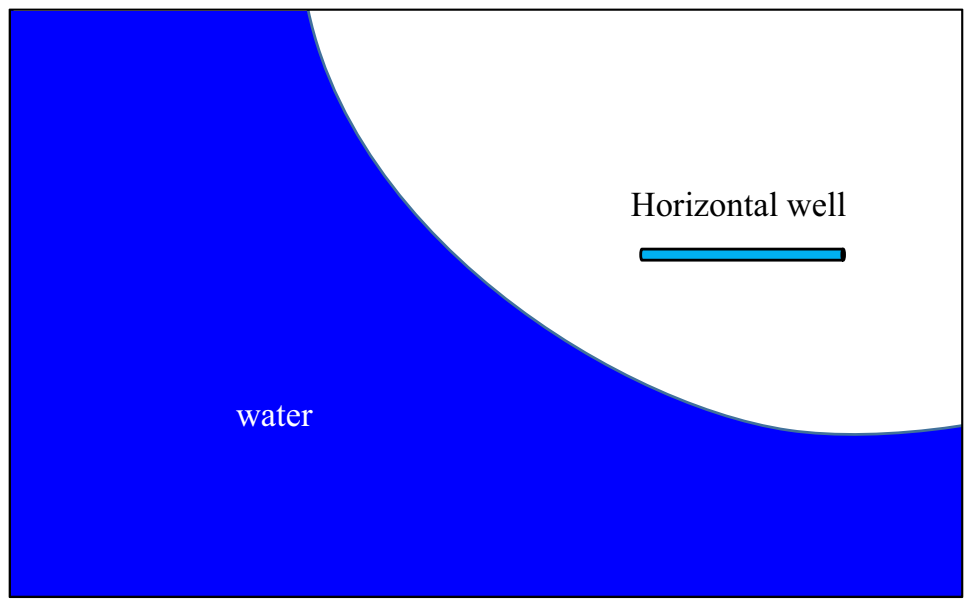

(a) Top view

Horizontal well

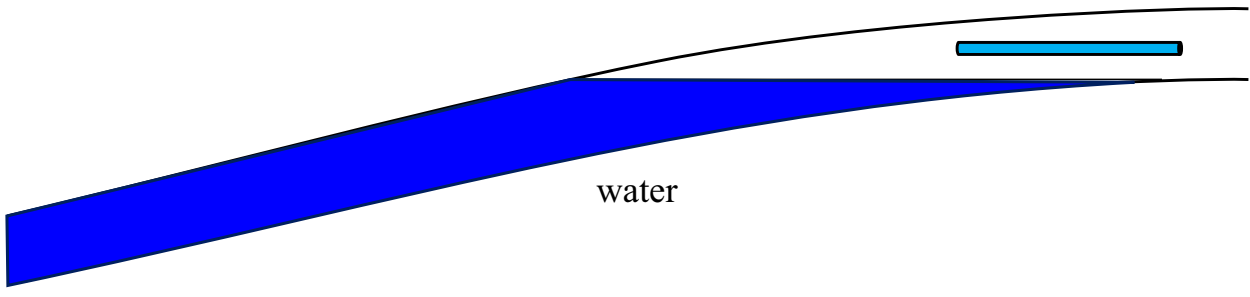

(b) Front view

production process of horizontal well in homogeneous bottom water reservoir, the distribution of water saturation is symmetrical along the wellbore of horizontal well. However, in Fig. 2(a), water saturation distribution in the horizontal wellbore is not symmetrical, but shifted to the left, which indicates that the fluid movement to the horizontal wellbore is affected by edge water.

In the production process of horizontal well in a reservoir, both edge water and bottom water have the energy to drive oil. Because bottom water is close to the horizontal well, the bottom water first drives oil to the horizontal well. Along the direction of horizontal wellbore, the thickness of bottom water gradually becomes thinner, and the driving energy gradually depletes, and then the edge water far away from the horizontal wellbore gradually supply energy to the bottom water for oil displacement. In order to calculate the productivity of horizontal well in a heterogeneous reservoir with composite water aquifer, vertical seepage of bottom water and lateral seepage of edge water must be considered. If the energy of bottom water is weak, the influence of edge water is obvious. The effective drainage distance of edge water are directly related with seepage resistance, which will obviously influence the productivity of horizontal well.
The productivity formula of horizontal well in the existing literature is for pure edge water or pure bottom water reservoir, which doesn't consider the influence of edge water on bottom water or the influence of bottom water on edge water. Due to the complexity of edge-bottom water distribution and the variation of reservoir property, conventional productivity formula of horizontal well in pure edge water or pure bottom water reservoir usually generate large errors. In order to improve the accuracy of horizontal well productivity formula, the mutual influence of edge water and bottom water must be considered. Applying the seepage mechanics theory and potential superposition principle, the productivity formula of horizontal well in heterogeneous reservoir with composite water aquifer is established. The new productivity formula considers the effect of reservoir heterogeneity, the quasi-linear flow of lateral edge water and the ellipsoidal flow of vertical bottom water. It can effectively determine the influence range and drainage distance of edge water in a heterogeneous reservoir with composite water aquifer. The calculation results of proposed formula in this paper are in good consistent with the productivity test data of horizontal well. 


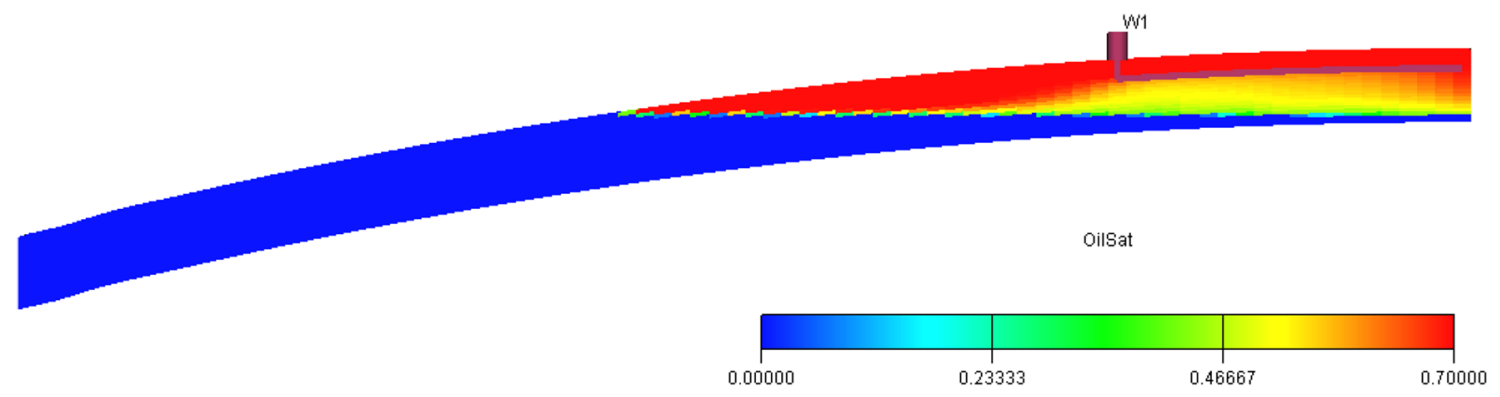

(a) Fluid mainly moves from bottom water to horizontal well

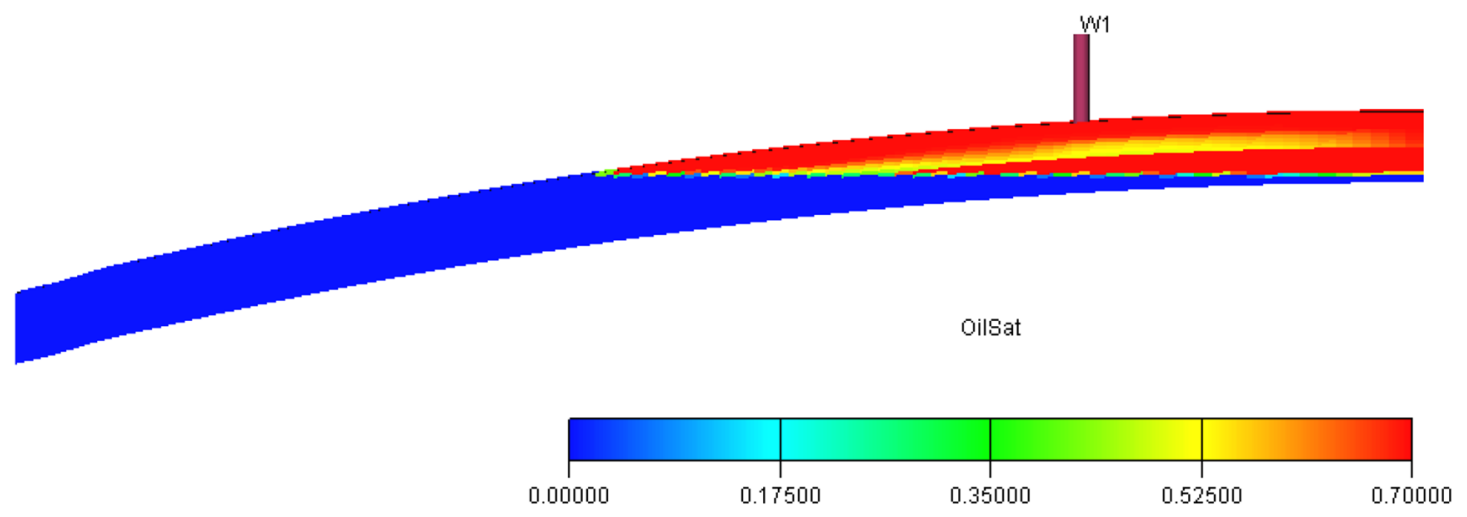

(b) Fluid mainly moves from edge water to horizontal well

Fig. 2 Fluid movement direction in a heterogeneous reservoir with composite water aquifer

\section{Review of horizontal well productivity formula}

\section{Joshi's formula}

Joshi (1988) divided the three-dimensional seepage field of horizontal well into the superposition of two-dimensional seepage fields in horizontal and vertical directions, and proposed the formula to calculate production rate of horizontal well.

$Q=\frac{0.543 k_{\mathrm{h}} h \cdot \Delta P}{\mu B\left[\ln \frac{a+\sqrt{a^{2}-(L / 2)^{2}}}{L / 2}+\frac{\beta h}{L} \ln \left(\frac{\beta h}{2 r_{\mathrm{w}}}\right)\right]}$

where

$$
\begin{aligned}
a & =\frac{L}{2} \sqrt{0.5+\sqrt{0.25+\left(2 R_{\mathrm{eh}} / L\right)^{4}}}, \quad \beta=\sqrt{k_{\mathrm{h}} / k_{\mathrm{v}}} \\
, r_{e h} & =\sqrt{A / \pi} .
\end{aligned}
$$

$Q$ is production rate of horizontal well, $\mathrm{m}^{3} / \mathrm{d} ; k_{\mathrm{h}}, k_{\mathrm{v}}$ are horizontal and vertical permeability of reservoir, $\mathrm{mD} ; h$ is reservoir thickness, $\mathrm{m} ; \Delta P$ is producing pressure difference,
$\mathrm{MPa} ; a$ is long half axis of ellipsoidal discharge area in horizontal well, $\mathrm{m}$; $L$ is length of horizontal well, $\mathrm{m} ; r_{\text {eh }}$ is discharge radius of horizontal well, $\mathrm{m} ; A$ is discharge area of horizontal well, $\mathrm{m}^{2} ; r_{\mathrm{w}}$ is well radius, $\mathrm{m} ; \beta$ is permeability anisotropy coefficient; $\mu$ is oil viscosity, $\mathrm{mPa} \mathrm{s} ; B$ is oil volume factor, $\mathrm{m}^{3} / \mathrm{m}^{3}$.

\section{Fan's formula}

Fan (1993) applied the conformal transform and potential function theory to derive the productivity formula of horizontal well in bottom-water reservoir with infinite extension in the horizontal direction.

$Q=\frac{0.543 k L}{\mu B} \frac{\Delta P}{\ln \frac{4 \beta h}{\pi r_{\mathrm{w}}}+\ln \tan \frac{\pi z_{\mathrm{w}}}{2 h}}$

where, $k=\sqrt{k_{\mathrm{h}} \cdot k_{\mathrm{v}}}, z_{\mathrm{w}}$ is vertical position of horizontal wellbore, $\mathrm{m}$.

Fan and Lin (1994) also derived the productivity formula of horizontal well in edge-water reservoir. 
$Q=\frac{0.7238 k L}{\mu B} \frac{\Delta P}{\ln \frac{\beta h}{2 \pi r_{\mathrm{w}}}+\frac{1.333 \pi b}{\beta h}-\ln \sin \frac{\pi z_{\mathrm{w}}}{h}}$

where, $b$ is the distance from edge water to horizontal wellbore, $\mathrm{m}$.

\section{Lü's formula}

Lü (1993) assumed that the reservoir is a rotating ellipsoid whose focal point is in the two ends of the horizontal well and the length of short half axis is reservoir thickness $h$. He derived the productivity formula of horizontal well in isotropic reservoir

$$
Q=\frac{1.0857 k L \cdot \Delta P}{\mu B \ln \left[\frac{2\left(\sqrt{L^{2}+h^{2}}-L\right) L^{2}}{\left(\sqrt{L^{2}+h^{2}}+L\right) r_{\mathrm{w}}^{2} \ln \frac{2 L}{r_{\mathrm{w}}}}\right]}
$$

In anisotropic reservoir, the productivity formula is

$$
Q=\frac{1.0857 k_{\mathrm{v}}^{0.75} k_{\mathrm{h}}^{0.25} \cdot L}{\mu B} \cdot \frac{\Delta P}{\ln \frac{1}{2}+2 \ln \left[\frac{4 L}{\left(\sqrt{k_{\mathrm{h}} / k_{\mathrm{v}}}+1\right) r_{\mathrm{w}}}\right]+A}
$$

$$
A=\ln \frac{\sqrt{k_{\mathrm{v}} L^{2}+k_{\mathrm{h}} h^{2}}-\sqrt{k_{\mathrm{v}}} L}{\sqrt{k_{\mathrm{v}} L^{2}-k_{\mathrm{h}} h^{2}}+\sqrt{k_{\mathrm{v}}} L}-\ln \ln \frac{4 L}{\left(\sqrt{k_{\mathrm{h}} / k_{\mathrm{v}}}+1\right) r_{\mathrm{w}}}
$$

The above formulas take into account the influence of anisotropy, but don't consider the influence of heterogeneity.
They also don't consider the common effects of edge water and bottom water. These formulas are not fully applicable to the horizontal well in a heterogeneous reservoir with composite water aquifer.

\section{Derivation of horizontal well productivity calculation model in heterogeneous reservoir with composite water aquifer}

The horizontal well model in heterogeneous reservoir with composite water aquifer is in Fig. 3. The top of reservoir is closed. The bottom water is below the horizontal well and the edge water is on the lateral side. Edge and bottom water act on horizontal well at the same time. Consider the common influences of edge water and bottom water, the threedimensional flow field of horizontal well can be approximately divided into internal and external two-dimensional flow fields. The external seepage field supplies oil from the drainage area with effective edge-water distance $b$ and boundary pressure of $P_{e}$ to the "straight tunnel" with length of $L$. The internal seepage field supplies oil from bottom water containing "straight tunnel" to the horizontal well with bottom hole pressure of $P_{w f}$ (Fig. 3).

In Fig. 3, the total length of horizontal section is $L$; the total production rate is $Q$. The steady seepage of incompressible fluid obeys Darcy's law. The production section of horizontal well is divided into $m$ sections from toe to heel. The length, permeability and production rate of section $i$ are $L(i)$ 、 $k(i) 、 Q(i)(i=1,2, \ldots, m)$ respectively. The coordinates of two ends for segment $i$ are $A_{\mathrm{i}}\left(x_{\mathrm{i} 1}, y_{\mathrm{i} 1}, z_{\mathrm{i} 1}\right)$ and $B_{\mathrm{i}}\left(x_{\mathrm{i} 2}, y_{\mathrm{i} 2}, z_{\mathrm{i} 2}\right)$.

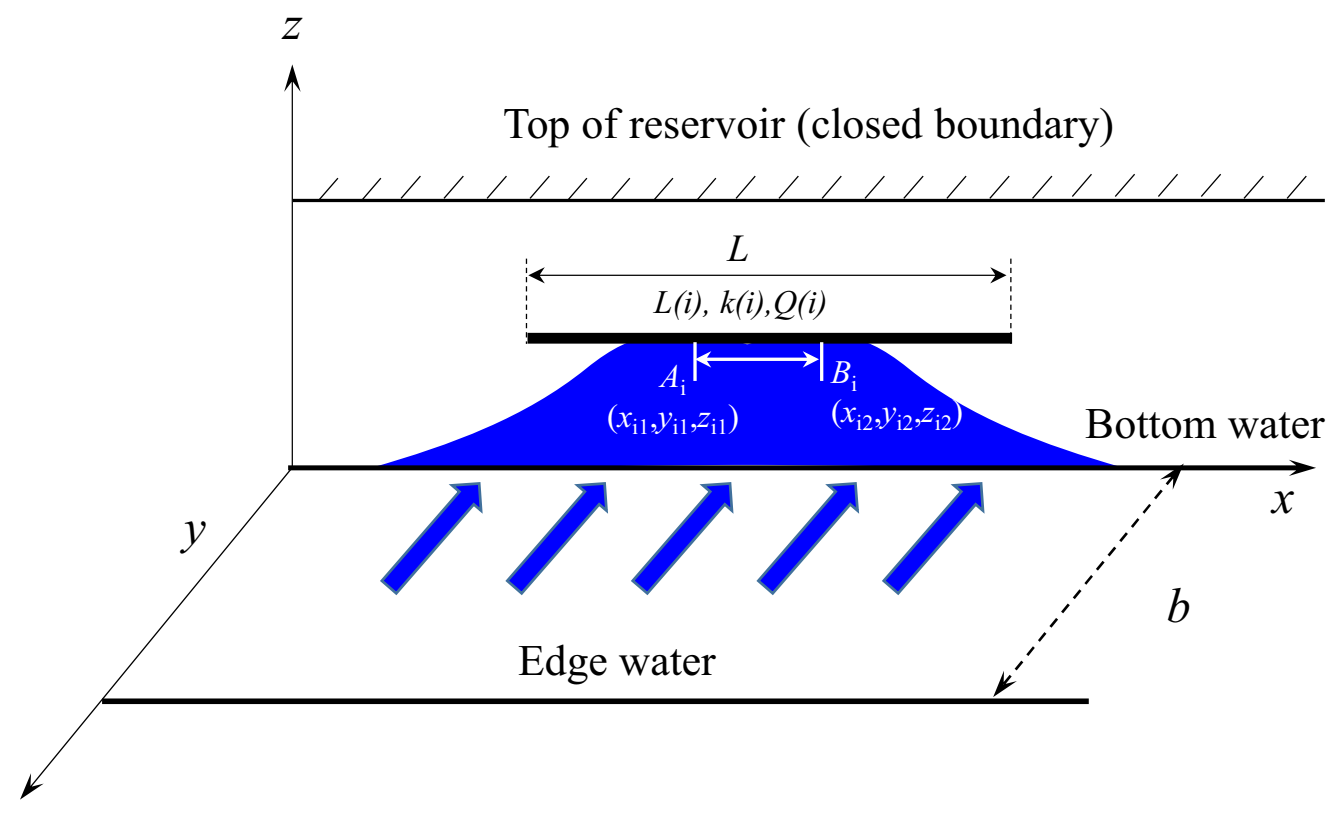

Fig. 3 The heterogeneous reservoir model with composite water aquifer 
The potential of horizontal well section $i$ in infinite threedimensional space is (Lü 1993; Qi et al. 2015):

$\Phi(i)=\frac{k(i)}{\mu B} P(i)+C=\frac{Q(i)}{1.0857 L(i)} \ln \frac{D(i)-L(i)}{D(i)+L(i)}+C$

where, $k(i)$ is permeability of horizontal well section $i, \mathrm{mD}$; $P(i)$ is pressure of horizontal well section $i, \mathrm{MPa} ; L(i)$ is length of horizontal section $i, \mathrm{~m} ; Q(i)$ is production rate of horizontal well section $i, \mathrm{~m}^{3} / \mathrm{d} ; D(i)$ is the sum of distances from any point in the reservoir to two ends of horizontal well section $L(i)$.

$S_{1}(x, y, z, i)=\sum_{n=-\infty}^{\infty}\left[\begin{array}{c}\ln \frac{D_{1}(x, y, z, n, i)+L_{i}}{D_{1}(x, y, z, n, i)-L_{i}}+\ln \frac{D_{2}(x, y, z, n, i)+L_{i}}{D_{2}(x, y, z, n, i)-L_{i}} \\ -\ln \frac{D_{3}(x, y, z, n, i)+L_{i}}{D_{3}(x, y, z, n, i)-L_{i}}-\ln \frac{D_{4}(x, y, z, n, i)+L_{i}}{D_{4}(x, y, z, n, i)-L_{i}}\end{array}\right]$
$\Delta \Phi_{1}(i, j)=\frac{k(j)}{\mu B} \cdot \Delta P_{1}(i, j)=\frac{Q(i)}{1.0857 L(i)}\left[W_{1}(i, j)-E_{1}(i, j)\right]$

For the permeability $k(j)$, the symbol $j$ is used to reflect the influence of well segment $j$ on well segment $i$.Where,

$W_{1}(i, j)=S_{1}\left[x(j), y_{i 1}, 0, i\right]$

$E_{1}(i, j)=S_{1}\left[x(j), y_{i 1}+2 b, 0, i\right]$

Equation (10) represents the function at the "straight tunnel" with length $L$, and Eq. (11) represents the function at the effective drainage distance of edge water $(y+2 b)$.where, the $S_{1}$ function is:
According to the superposition principle of potential, the potential generated at any point in the reservoir for the whole horizontal well is:

$\Phi=\sum_{i=1}^{m} \Phi(i)+C$

The potential function is obtained in the external seepage field and internal seepage field respectively.

\section{External flow field}

As shown in Fig. 3, the external seepage field is from the effective drainage distance of edge water $y+b$ to the "straight tunnel" with length of $L$. For the external seepage field, the top and bottom of reservoir are seen as closed boundaries, and the reservoir is an edge-water reservoir. Considering the interferences between well segments $i$ and $j$ and referring to the form of Eq. (7), the potential difference function is
In Eq. (12), $D_{1}$ and $D_{2}$ are the functions of production well segment $i$ after mirror reflection through the top and bottom boundary of reservoir.

$D_{1}(x, y, z, n, i)=\sqrt{\left[x-x_{i 1}(i)\right]^{2}+\left(y-y_{i 1}\right)^{2}+\left[z-\left(2 n h+z_{i 1}\right)\right]^{2}}$
$+\sqrt{\left[x-x_{i 2}(i)\right]^{2}+\left(y-y_{i 2}\right)^{2}+\left[z-\left(2 n h+z_{i 2}\right)\right]^{2}}$

$D_{2}(x, y, z, n, i)=\sqrt{\left[x-x_{i 1}(i)\right]^{2}+\left(y-y_{i 1}\right)^{2}+\left[z-\left(2 n h-z_{i 1}\right)\right]^{2}}$

$+\sqrt{\left[x-x_{i 2}(i)\right]^{2}+\left(y-y_{i 2}\right)^{2}+\left[z-\left(2 n h-z_{i 2}\right)\right]^{2}}$

The image of real production well segment $i$ through the edge-water interface is an injection well segment with injection rate of $-Q(i)$, whose $x$-coordinate and $z$-coordinate on both ends are the same as that of real production well segment $i$, while $y$ coordinate is $y+2 b$. For the image injection well segment $i$, after mirror reflection through the top and bottom boundary of reservoir, the functions of $D_{3}$ and $D_{4}$ are

$$
\begin{aligned}
& D_{3}(x, y, z, n, i)=\sqrt{\left[x-x_{i 1}(i)\right]^{2}+\left[y-\left(y_{i 1}+2 b\right)\right]^{2}+\left[z-\left(2 n h+z_{i 1}\right)\right]^{2}} \\
& +\sqrt{\left[x-x_{i 2}(i)\right]^{2}+\left[y-\left(y_{i 2}+2 b\right)\right]^{2}+\left[z-\left(2 n h+z_{i 2}\right)\right]^{2}} \\
& D_{4}(x, y, z, n, i)=\sqrt{\left[x-x_{i 1}(i)\right]^{2}+\left[y-\left(y_{i 1}+2 b\right)\right]^{2}+\left[z-\left(2 n h-z_{i 1}\right)\right]^{2}} \\
& +\sqrt{\left[x-x_{i 2}(i)\right]^{2}+\left[y-\left(y_{i 2}+2 b\right)\right]^{2}+\left[z-\left(2 n h-z_{i 2}\right)\right]^{2}}
\end{aligned}
$$


where, $x(j)=x_{i 1}(j)+\frac{L}{2 m}, x_{i 1}(i)=(i-1) L / m, x_{i 2}(i)=i L / m$.

\section{Internal seepage field}

As shown in Fig. 3, the internal seepage field is from bottom water containing a "straight tunnel" to a horizontal well with bottom hole pressure of $P_{\mathrm{wf}}$. For the internal seepage field,
$D_{3}^{\prime}$ and $D_{4}^{\prime}$ are the functions of injection well segment $i$ after mirror reflection through the top and bottom boundary of reservoir.

$$
\begin{aligned}
D_{3}^{\prime}(x, y, z, n, i)= & \sqrt{\left[x-x_{i 1}(i)\right]^{2}+\left(y-y_{i 1}\right)^{2}+\left[z-\left(4 n h-z_{i 1}\right)\right]^{2}} \\
& +\sqrt{\left[x-x_{i 2}(i)\right]^{2}+\left(y-y_{i 2}\right)^{2}+\left[z-\left(4 n h-z_{i 2}\right)\right]^{2}}
\end{aligned}
$$

the top of the reservoir is a closed boundary, and the bottom is constant pressure boundary.

Considering the interferences between well sections $i$ and $j$, the potential difference function is

$\Delta \Phi_{2}(i, j)=\frac{k(j)}{\mu B} \cdot \Delta P_{2}(i, j)=\frac{Q(i)}{1.0857 L(i)}\left[W_{2}(i, j)-E_{2}(i, j)\right]$

where,

$W_{2}(i, j)=\left\{\begin{array}{l}S_{2}\left[x(j), y_{i 1}, \frac{z_{i 1}+z_{i 2}}{2}+r_{w}, i\right] i=j \\ S_{2}\left[x(j), y_{i 1}, \frac{z_{i 1}+z_{i 2}}{2}, i\right] i \neq j\end{array}\right.$

$E_{2}(i, j)=S_{2}\left[x(j), y_{i 1}, 0, i\right]$

Equations (18) and (19) are the functions at horizontal wellbore and the oil-water interface of bottom water $(z=0)$. The $S_{2}$ function is:

\section{Calculation of production rate}

For the horizontal well with $m$ segments in a heterogeneous reservoir with composite water aquifer, considering the interferences of well section $j$ on well section $i$, the total potential difference function is

$\Delta \Phi(i, j)=\Delta \Phi_{1}(i, j)+\Delta \Phi_{2}(i, j)$

The inverse matrix of productivity index is obtained from Eqs. (9) and (17)

$A(i, j)=\frac{\mu B}{1.0857 k(j)}\left\{\frac{m}{L}\left[W_{1}(i, j)-E_{1}(i, j)\right]+\frac{m}{L}\left[W_{2}(i, j)-E_{2}(i, j)\right]\right\}$

Production pressure difference matrix of well section $i$ is

$C(i)=P_{e}-P_{w}(i)$

where, $P_{e}$ is formation pressure, $\mathrm{MPa} ; P_{w}$ is bottom hole pressure, $\mathrm{MPa}$.

$S_{2}(x, y, z, i)=\sum_{n=-\infty}^{\infty}\left[\begin{array}{c}\ln \frac{D_{1}^{\prime}(x, y, z, n, i)+L_{i}}{D_{1}^{\prime}(x, y, z, n, i)-L_{i}}+\ln \frac{D_{2}^{\prime}(x, y, z, n, i)+L_{i}}{D_{2}^{\prime}(x, y, z, n, i)-L_{i}} \\ -\ln \frac{D_{3}^{\prime}(x, y, z, n, i)+L_{i}}{D_{3}^{\prime}(x, y, z, n, i)-L_{i}}-\ln \frac{D_{4}^{\prime}(x, y, z, n, i)+L_{i}}{D_{4}^{\prime}(x, y, z, n, i)-L_{i}}\end{array}\right]$

$D_{1}^{\prime}$ and $D_{2}^{\prime}$ are the functions of production well segment $i$ after mirror reflection through the top and bottom boundary of reservoir.

$$
\begin{aligned}
& D_{1}^{\prime}(x, y, z, n, i)=\sqrt{\left[x-x_{i 1}(i)\right]^{2}+\left(y-y_{i 1}\right)^{2}+\left[z-\left(4 n h+z_{i 1}\right)\right]^{2}} \\
& +\sqrt{\left[x-x_{i 2}(i)\right]^{2}+\left(y-y_{i 2}\right)^{2}+\left[z-\left(4 n h+z_{i 2}\right)\right]^{2}}
\end{aligned}
$$

$$
\begin{aligned}
& D_{2}^{\prime}(x, y, z, n, i)=\sqrt{\left[x-x_{i 1}(i)\right]^{2}+\left(y-y_{i 1}\right)^{2}+\left[z-\left(4 n h+2 h-z_{i 1}\right)\right]^{2}} \\
& +\sqrt{\left[x-x_{i 2}(i)\right]^{2}+\left(y-y_{i 2}\right)^{2}+\left[z-\left(4 n h+2 h-z_{i 2}\right)\right]^{2}}
\end{aligned}
$$

Production rate matrix of well section $i$ is

$Q(i)=A(i, j)^{-1} \cdot C(i)$

Actually, Eq. (28) is a matrix expression form of productivity equation for well section $i$. The total production rate of horizontal well is

$Q=\sum_{i=1}^{m} Q(i)$

If the reservoir is anisotropic, let $\beta=\sqrt{k_{h}(j) / k_{v}(j)}$, and substitute $\sqrt{k_{h}(j) \cdot k_{v}(j)}, \beta h$ and $\beta z$ for $k(j), h$ and $z$ in above 
formulas. Then, the potential difference and production rate of horizontal well in anisotropic reservoirs can be obtained.

\section{Result analysis}

\section{Analysis of theoretical curve features}

Because of the influence of reservoir heterogeneity, the distribution of flow rate along horizontal well section is nonuniform. Accurate prediction of flow rate distribution is helpful to adopt reasonable production technology for horizontal well. Basic parameters of a reservoir are as follows: permeability $k=400 \mathrm{mD}$, pay thickness $h=15 \mathrm{~m}$, oil viscosity $\mu_{\mathrm{o}}=40 \mathrm{mPa}$.s, volume factor $B_{o}=1.05 \mathrm{~m}^{3} / \mathrm{m}^{3}$, horizontal well length $L=600 \mathrm{~m}$, well radius $r_{w}=0.1 \mathrm{~m}$, edge water influence distance $b=60 \mathrm{~m}$. Because the influence of permeability on flow rate distribution of horizontal well is more obvious than other parameters, firstly the sensitivity analyses on permeability are done.

Under homogeneous condition, the productivity index of horizontal well is $75.17 \mathrm{~m}^{3} /(\mathrm{d} . \mathrm{MPa})$. The distribution of productivity index along the horizontal well section is shown in Figs. 4, 5, 6 and 7. The results show that under homogeneous conditions (Fig. 4), the distribution of flow rate along horizontal well section is U-shaped, with less flow rate in the middle and more at both ends, which is caused by larger oil drainage area at both ends of horizontal well. Setting the permeability increasing gradually from heel to toe of horizontal well section but the average permeability unchanged,
Fig. 4 The relationship between productivity index and permeability of horizontal well section in homogeneous reservoir

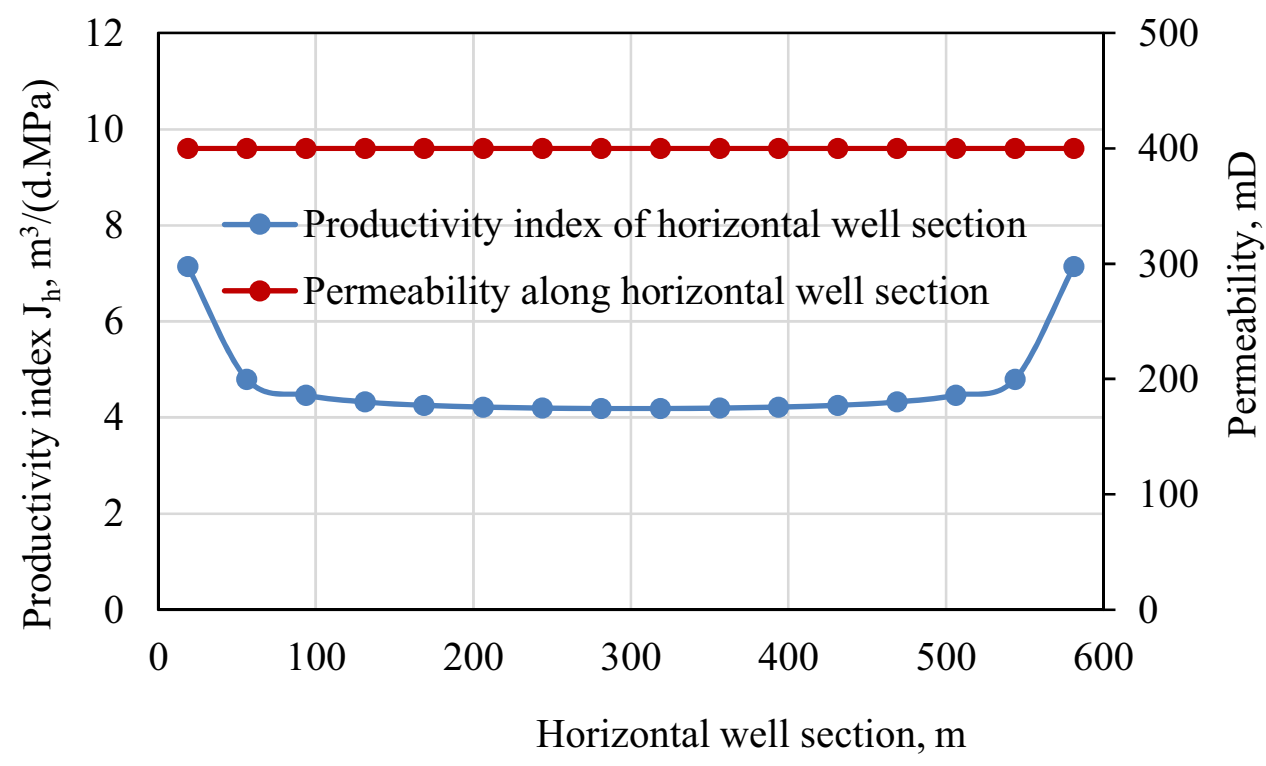

Horizontal well section, $\mathrm{m}$

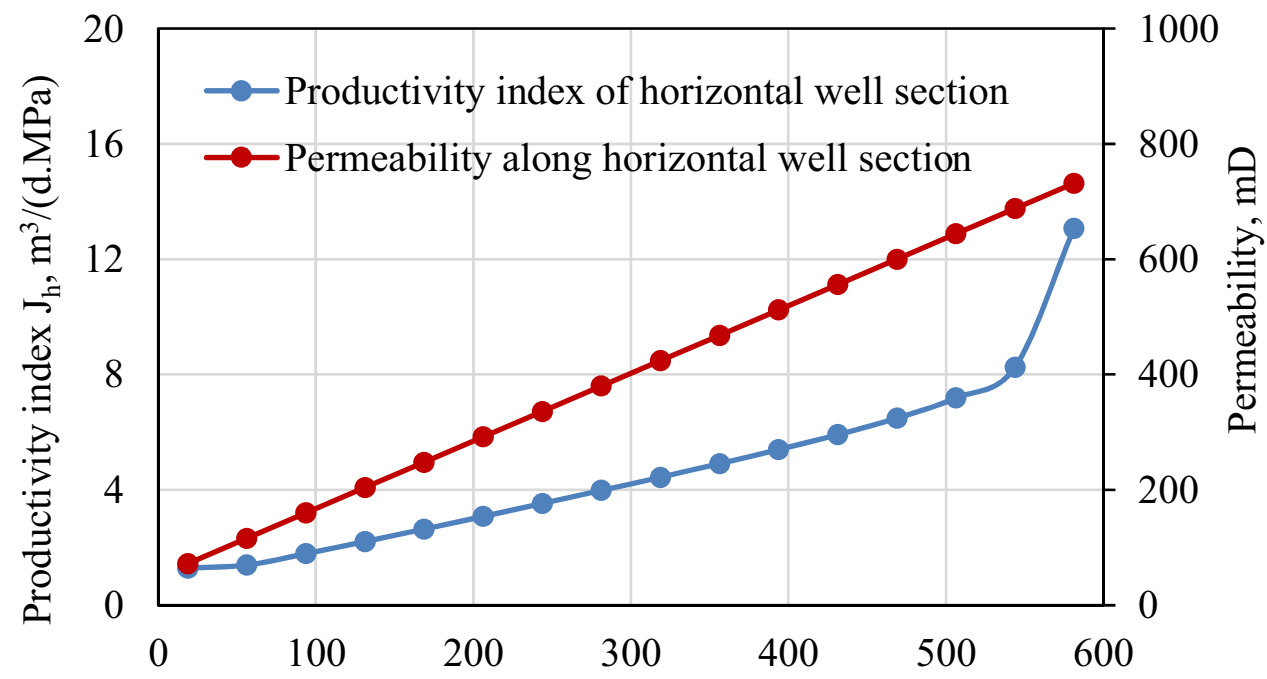

Horizontal well section, $\mathrm{m}$
Fig. 5 The relationship between productivity index and permeability of horizontal well section in heterogeneous reservoir (Permeability increases from heel to toe)

\section{高}

हี


Fig. 6 The relationship between productivity index and permeability of horizontal well section in heterogeneous reservoir (Permeability from heel to toe increases first and then decreases)

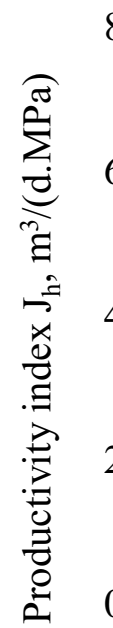

8

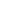

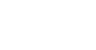

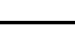


Fig. 8 The production index of horizontal well under different drainage distance of edge water

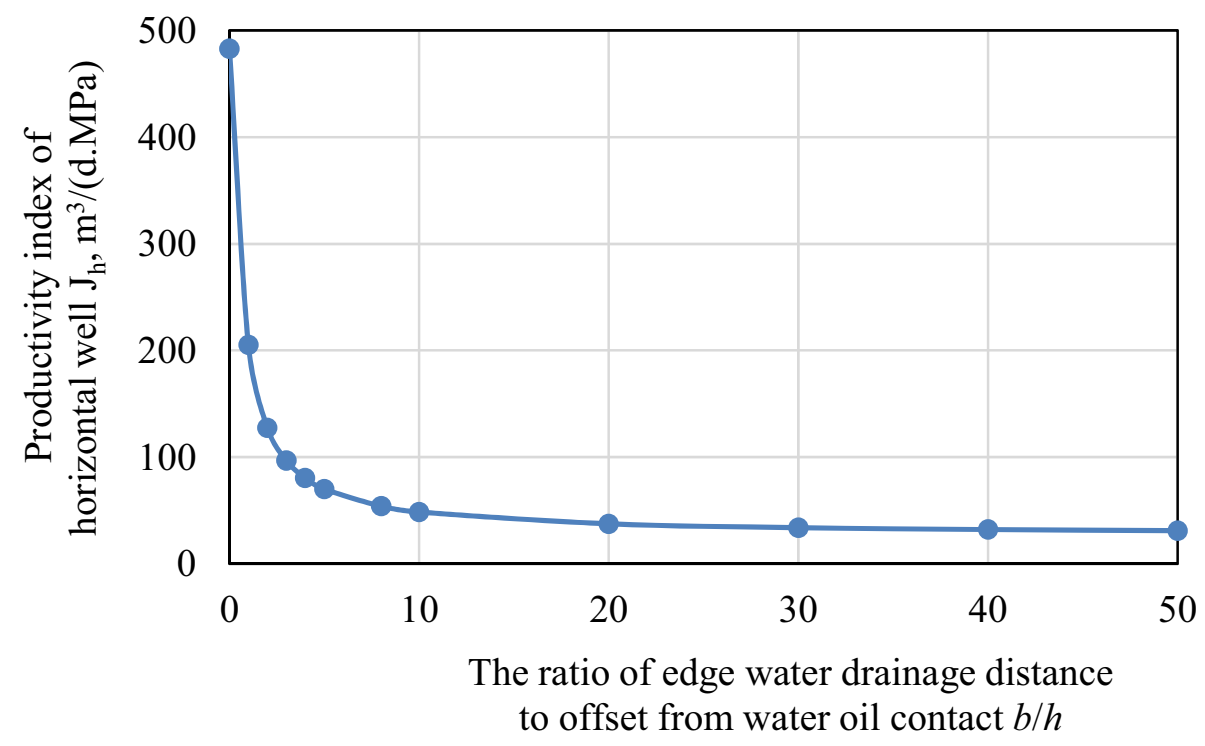

Table 1 Comparison of productivity calculation results of horizontal wells in Weizhou 11-1 Oilfield

\begin{tabular}{|c|c|c|c|c|c|c|c|}
\hline \multirow[t]{2}{*}{$\begin{array}{l}\text { Well } \\
\text { name }\end{array}$} & \multicolumn{3}{|l|}{ Parameters } & \multirow[t]{2}{*}{$\begin{array}{l}\text { Actual productivity index } \\
J_{h}, \mathrm{~m}^{3} /(\mathrm{d} . \mathrm{MPa})\end{array}$} & \multicolumn{3}{|c|}{$\begin{array}{l}\text { Calculated productivity index } J_{h}, \mathrm{~m}^{3} / \\
\text { (d.MPa) }\end{array}$} \\
\hline & $\begin{array}{l}\text { Permeability } \\
k, \mathrm{mD}\end{array}$ & $\begin{array}{l}\text { Pay thickness } \\
h, \mathrm{~m}\end{array}$ & $\begin{array}{l}\text { Length of } \\
\text { horizontal } \\
\text { well L, m }\end{array}$ & & $\begin{array}{l}\text { Joshi's } \\
\text { formula }\end{array}$ & $\begin{array}{l}\text { Fan's } \\
\text { formula }\end{array}$ & Lü's formula \\
\hline $\mathrm{A} 13 \mathrm{H}$ & 165.5 & 12.2 & 487 & 39.88 & 15.60 & 176.45 & 51.51 \\
\hline $\mathrm{A} 14 \mathrm{H}$ & 362.0 & 12.3 & 719 & 58.05 & 41.81 & 569.64 & 167.00 \\
\hline $\mathrm{A} 22 \mathrm{H}$ & 273.0 & 8.2 & 626 & 59.59 & 22.78 & 400.17 & 122.77 \\
\hline $\mathrm{A} 23 \mathrm{H}$ & 438.7 & 8.2 & 284 & 36.63 & 21.12 & 292.06 & 88.23 \\
\hline A8S2 & 438.4 & 11.5 & 385 & 53.73 & 30.64 & 373.41 & 109.19 \\
\hline
\end{tabular}

the ratio of edge water drainage distance to offset from water oil contact is $0 \sim 10$, the change of horizontal well productivity index is very sensitive. For the horizontal well in a reservoir with composite water aquifer, if the drainage distance of edge water is several times of offset from water oil contact, the process that edge water supplies energy to bottom water for oil displacement cannot be ignored.

\section{Case analysis}

Weizhou 11-1 oilfield is located in the Weixinan Sag, Beibu Gulf Basin, South China Sea. It is an anticline structural reservoir with low amplitude and shallow buried depth of $942 \sim 980 \mathrm{~m}$. The horizontal wells in Weizhou 11-1 oilfield have obvious features of edge-bottom water drive. Oil viscosity is $38.50 \mathrm{mPa} \mathrm{s}$, and oil volume factor is $1.05 \mathrm{~m}^{3} / \mathrm{m}^{3}$. Reservoir permeability, pay thickness and effective length of horizontal well section are shown in Table 1. Considering the anisotropy of reservoir, take $k_{\mathrm{v}} / k_{\mathrm{h}}=0.1$.
Table 2 Fitting of effective edge water drainage distance in Weizhou 11-1 Oilfield

\begin{tabular}{lll}
\hline Well name & $\begin{array}{l}\text { Actual productivity index } \\
J_{h}, \\
\mathrm{~m}^{3} /(\mathrm{d} \mathrm{MPa})\end{array}$ & $\begin{array}{l}\text { Parameter fitting } \\
\text { Edge water } \\
\text { drainage dis- } \\
\text { tance } b, \mathrm{~m}\end{array}$ \\
\hline $\mathrm{A} 13 \mathrm{H}$ & 39.88 & 27.5 \\
$\mathrm{~A} 14 \mathrm{H}$ & 58.05 & 80 \\
A22H & 59.59 & 28 \\
Average & & 45.17 \\
\hline
\end{tabular}

The calculation results of different formulas show that Fan's and Lü's formulas don't consider the seepage resistance of edge water, therefore the calculation results are bigger than actual productivity index. The pseudo-radial flow in the plane is considered in Joshi's formula, but its drainage radius is larger than the effective drainage distance of edge water, resulting in larger seepage resistance and lower productivity index of horizontal wells. 
Table 3 Prediction results of horizontal well productivity index in Weizhou 11-1 oilfield

\begin{tabular}{|c|c|c|c|c|}
\hline \multirow[t]{2}{*}{ Well name } & \multirow{2}{*}{$\begin{array}{l}\text { Actual } \\
\text { productivity } \\
\text { index } J_{h}, \\
\mathrm{~m}^{3} /(\mathrm{d} \mathrm{MPa})\end{array}$} & \multicolumn{3}{|c|}{$\begin{array}{l}\text { Predicted productivity index } J_{h}, \mathrm{~m}^{3} / \\
(\mathrm{d} \mathrm{MPa})\end{array}$} \\
\hline & & $\begin{array}{l}\text { Prediction } \\
\text { parameter }\end{array}$ & $\begin{array}{l}\text { Prediction } \\
\text { results }\end{array}$ & Error, \% \\
\hline $\mathrm{A} 23 \mathrm{H}$ & 36.63 & $b=45.17$ & 34.23 & -6.56 \\
\hline $\mathrm{A} 8 \mathrm{~S} 2$ & 53.73 & & 57.67 & 7.34 \\
\hline
\end{tabular}

The productivity formula proposed in this paper takes into account the influence range and drainage distance $b$ of edge water in a heterogeneous reservoir with composite water aquifer. If the water is mainly at the bottom of oil well or the energy of bottom water aquifer is strong, water mainly flows in the vertical direction and the effective edgewater drainage distance $b$ is small. If the water is mainly at the edge of oil well or the energy or edge water aquifer is strong, water mainly flows in the horizontal direction and the effective edge-water drainage distance $b$ is big. In actual reservoir, due to the unclear recognitions about oil-water contact relationship and energy of composite edge-bottom water aquifer, the parameter $b$ is difficult to determine. In the process of practical application, the drainage distance $b$ of edge water can be fitted according to existing test data, and then it can be used as a known parameter to predict the productivity index of new wells. As shown in Table 2, according to test data of productivity index, the edge water drainage distances of well $\mathrm{A} 13 \mathrm{H}, \mathrm{A} 14 \mathrm{H}$ and $\mathrm{A} 22 \mathrm{H}$ are $27.5 \mathrm{~m}$, $80 \mathrm{~m}$ and $28 \mathrm{~m}$ respectively, with an average of $45.17 \mathrm{~m}$. The prediction errors of well $\mathrm{A} 23 \mathrm{H}$ and $\mathrm{A} 8 \mathrm{~S} 2$ are $-6.56 \%$ and $7.34 \%$ (Table 3). Compared with Table 1, the prediction accuracy is greatly improved.

\section{Conclusions}

1. Based on the seepage mechanics theory and potential superposition principle, considering the mutual interference between multi well sections, the productivity formula of horizontal well in heterogeneous reservoir with composite water aquifer is established. The new productivity formula considers the influence of reservoir heterogeneity, the quasi-linear flow of lateral edge water and the ellipsoidal flow of vertical bottom water. It can effectively determine the influence range and drainage distance of edge water in a heterogeneous reservoir with composite water aquifer.

2. Under homogeneous condition, the distribution of flow rate at both ends of horizontal well section is high but it is low in the middle. If the permeability from heel to toe increases first and then decreases, the high flow rate at the end of horizontal well is restrained, resulting in the decrease of productivity index of the whole horizontal well section. If the permeability from heel to toe decreases first and then increases, the distribution of bigger flow rate at the end of horizontal well section is enhanced, resulting in the increase of productivity index of the whole horizontal well section.

3. In the reservoir with composite water aquifer, with the increase of edge water drainage distance, the productivity index of horizontal well first decreases sharply, then tends to be stable gradually. When the ratio of edge water drainage distance to offset from water oil contact is $0 \sim 10$, the change of horizontal well productivity index is very sensitive. For the horizontal well in a reservoir with composite water aquifer, if the drainage distance of edge water is several times of offset from water oil contact, the process that edge water supplies energy to bottom water for oil displacement cannot be ignored.

4. According to the test data of horizontal wells in Weizhou 11-1 oilfield, the average edge water drainage distance of well $\mathrm{A} 13 \mathrm{H}, \mathrm{A} 14 \mathrm{H}$ and $\mathrm{A} 22 \mathrm{H}$ is $45.17 \mathrm{~m}$. It is used to predict the productivity index of well $\mathrm{A} 23 \mathrm{H}$ and $\mathrm{A} 8 \mathrm{~S} 2$, whose accuracy is greatly improved with errors of $-6.56 \%$ and $7.34 \%$. The method has good application prospect in the productivity prediction of horizontal well in similar reservoir.

Funding The authors thank National Science and Technology Major Projects (2016ZX05058-003-017), Chongqing Natural Science Foundation Project (cstc2019jcyj-msxmX0331, cstc2019jcyj-zdxmX0032), Science and Technology Research Project of Chongqing Municipal Education Committee (KJQN202001501), Comprehensive scientific research project of CNOOC (YXKY-2019-ZJ-03) for supporting this work.

Open Access This article is licensed under a Creative Commons Attribution 4.0 International License, which permits use, sharing, adaptation, distribution and reproduction in any medium or format, as long as you give appropriate credit to the original author(s) and the source, provide a link to the Creative Commons licence, and indicate if changes were made. The images or other third party material in this article are included in the article's Creative Commons licence, unless indicated otherwise in a credit line to the material. If material is not included in the article's Creative Commons licence and your intended use is not permitted by statutory regulation or exceeds the permitted use, you will need to obtain permission directly from the copyright holder. To view a copy of this licence, visit http://creativecommons.org/licenses/by/4.0/.

\section{References}

Adewole ES (2014) Theoretical breakthrough time of horizontal wells subject to external fluid drive in a layered reservoir with varying architecture; part V: letter 'E' architecture. In: SPE Nigeria annual 
international conference and exhibition, 5-7 August, Lagos, Nigeria, SPE-172836-MS

Akangbou HN, Burby M, Nasr G (2017) Effectively optimizing production of horizontal wells in homogeneous oil reservoirs. J Pet SciEng 150:128-136

Al Zarafi A (1993) Breathing new life into a thin oil column by horizontal drilling. In: Middle East oil show, 3-6 April, Bahrain, SPE-25532-MS

Al-Enezi K, Das OP, Aslam M, et al (2010) Water coning model for horizontal wells in high mobility reservoir, west Kuwait. In: International oil and gas conference and exhibition in China, 8-10 June, Beijing, China, SPE-130302-MS

Al-Fatlawi O, Hossain M, Essa A (2019) Optimization of fracture parameters for hydraulic fractured horizontal well in a heterogeneous tight reservoir: an equivalent homogeneous modelling approach. In: SPE Kuwait oil \& gas show and conference, Mishref, Kuwait, SPE-198185-MS

Chaperon I (1986) Theoretical study of coning toward horizontal and vertical wells in anisotropic formations: subcritical and critical rates. In: SPE annual technical conference and exhibition, 5-8 October, New Orleans, Louisiana, SPE-15377-MS

Fan Z (1993) Study for horizontal well's productivity formula in bottom-water drive reservoir. Pet Explor Dev 20(1):71-75 ((in Chinese))

Fan Z, Lin Z (1994) Productivity formula of horizontal well in reservoirs with edge water drive. Pet Geol Oilfield Dev Daqing 13(2):33-37 ((in Chinese))

Giger FM (1989) Analytic two-dimensional models of water cresting before breakthrough for horizontal wells. SPE ReservEng 4(4):409-416 (SPE-15378-PA)

Hagoort J (2009) A simplified analytical method for estimating the productivity of a horizontal well producing at constant rate or constant pressure. J Pet SciEng 64(1-4):77-87

Huo J, Shi G, Lu J, et al. (2010) The horizontal well production technique with thin bedded bottom water reservoir in Luliang oil field. In: International oil and gas conference and exhibition in China, 8-10 June, Beijing, China, SPE-131890-MS

Joshi SD (1988) Augmentation of well productivity with slant and horizontal wells. In: SPE annual technical conference and exhibition, 5-8 October, New Orleans, Louisiana. SPE-15375-MS

Kumar M, Sharma P, Gupta DK (2017) Sensitivity study of horizontal length, offset from water oil contact and withdrawal rate of horizontal well in bottom water drive reservoir. J Pet Explor Prod Technol 8:577-588
Lü J (1993) An analytical solution of steady—state flow equation for the productivity of a horizontal well. Pet Explor Dev 20:135-140 ((in Chinese))

Luo W, Li HT, Wang YQ et al (2015) A new semi-analytical model for predicting the performance of horizontal wells completed by inflow control devices in bottom-water reservoirs. J Nat Gas SciEng 27(3):1328-1339

Nobakht M, Ambrose R, Clarkson CR et al (2013) Effect of completion heterogeneity in a horizontal well with multiple fractures on the long-term forecast in shale-gas reservoirs. J Can Pet Technol 52(6):417-425

Permadi P, Jayadi T (2010) An improved water coning calculation for horizontal wells. In: SPE Russian oil and gas conference and exhibition, 26-28 October, Moscow, Russia, SPE-133162-MS

Qi Z, Liang B, Yan W et al (2015) An approach to calculating snake well productivity under steady-state flow. J Nat Gas SciEng 27(3):1340-1347

Sharma P, Kumar M, Gupta DK (2019) 3D numerical simulation of clastic reservoir with bottom water drive using various IOR techniques for maximizing recovery. J Pet Explor Prod Technol 9:1075-1087

Su YC, Shi HF, He YF (2018) A new method to calculate sweep efficiency of horizontal wells in heterogeneous reservoir. J Pet Explor Prod Technol 9:2019-2026

Wang Y, Liu H, Chen $\mathrm{Z}$ et al (2018) A visualized investigation on the mechanisms of anti-water coning process using nitrogen injection in horizontal wells. J Pet SciEng 166:636-649

Wibowo W, Permadi P, Mardisewojo P, et al. (2004) Behavior of water cresting and production performance of horizontal well in bottom water drive reservoir: A scaled model study. In: SPE asia pacific conference on integrated modelling for asset management, 29-30 March, Kuala Lumpur, Malaysia, SPE-87046-MS

You Q, Wen Q, Fang J et al (2019) Experimental study on lateral flooding for enhanced oil recovery in bottom-water reservoir with high water cut. J Petrol SciEng 174:747-756

Yue P, Jia B, Sheng J et al (2019) A coupling model of water breakthrough time for a multilateral horizontal well in a bottom waterdrive reservoir. J Petrol SciEng 177:317-330

Publisher's Note Springer Nature remains neutral with regard to jurisdictional claims in published maps and institutional affiliations. 